\title{
Diagnóstico clínico da doença cárie
}

\author{
Berenice Barbachan e Silva* \\ Eloá Rossoni* *
}

\section{RESUMO}

Este artigo tem como objetivo uma revisāo da literatura a respeito do diagnóstico clínico e decisāo de tratamento da doença cárie. $\mathrm{O}$ avanço científico nesta área nos permite, atualmente, uma análise crítica sobre como vêm sendo realizados, historicamente, estes procedimentos. Até bem pouco tempo, o diagnóstico da doença cárie era realizado visando a detecçảo de cavidades e o tratamento consistia simplesmente na restauraçāo destas lesōes, resultando, assim, em uma abordagem sintomática da doença. Mais recentemente, vem se procurando trabalhar na análise e controle dos fatores etiológicos determinantes da doença, fazendo com que se interfira no seu surgimento e progressāo e o tratamento passe a ser voltado para a causa.

\section{SUMMARY}

The aim of this research is a literature revision about clinical diagnostic and treatment decision of caries disease. The increase of the cientific knowledge in this area allows, nowadays, a critic analysis about how have been realized, historically, this procedures, in many times, the diagnostic and the treatment of the caries disease are still realized with the objective of looking for cavities, that results only a symptomatic interference in the disease. In these time, professionals who work with oral health have the purpose of controlling the caries disease process and make that the treatment must be directed to its etiology.

\section{UNITERMOS}

\author{
Diagnóstico, cárie dentária
}

\section{Introdução}

A cárie é atualmente reconhecida como uma doença infecto-contagiosa que causa a destruição localizada dos tecidos dentais mineralizados. A doença pode afetar o esmalte, a dentina e o cemento $(14,28,31)$.

A destruição tecidual da estrutura dentária é causada pelos ácidos orgânicos, em especial o ácido láctico. Estes são produzidos por microrganismos que fermentam carboidratos sobre a superfície dentária. Apesar das grandes diferenças de composição e estrutura entre o esmalte, o cemento e a dentina, existe basicamente um padrão semelhante de fenômenos físico-químicos na determinação da expansão da cárie nestes tecidos $(28,31)$.

As lesōes cariosas são sintomas da doença que podem ser distribuídos em uma escala que vai desde perdas incipientes à nível ultraestrutural até a destruição total do dente, se o processo não for interrompido $(27,28)$.

Geralmente, a superfície afetada primeiramente é a oclusal. A cárie inicia-se nas fissuras, onde os mi- crorganismos se acumulam à medida que o dente irrompe. Os microrganismos que colonizam a superfície lisa do dente deverão ter propriedades específicas de aderência para não serem removidos pela ação da saliva ou mastigação. Apenas poucas espécies de microrganismos da cavidade bucal exibem esta capacidade e destes um grupo limitado é cariogênico. Estudos têm mostrado que o S. mutans é um importante microrganismo na iniciação da cárie dentária. Outro microrganismo importante é o lactobacilo, que em pesquisas ficou demonstrado estar correlacionado com a progressão da cárie dentária $(17,23)$.

Sendo a cárie, uma doença multifatorial, além da microflora cariogênica, outros fatores devem ser considerados: um substrato adequado para as bactérias e um hospedeiro suscetível. Uma redução na atividade de cárie pode consequentemente ser adquirida pela influência em pelo menos um destes três fatores: a resistência do hospedeiro, a dieta ou os microrganismos cariogênicos
(32)

É óbvio portanto que um diagnóstico baseado somente nos sintomas da doença, sem levar em conta a inter-relaçăo entre estes fatores correrá o risco de que as decisōes de tratamento e o julgamento do prognóstico da doença não sejam adequados $(16,28)$.

Atualmente é reconhecido que o tratamento sintomático das lesōes cariosas através da remoção da porção cariada e substituição da substância dentária perdida por uma restauraçăo ou coroa por si só não cura a doença.

O tratamento adequado da cárie dentária depende portanto de um

* Professora Auxiliar de Ensino do Departamento de Odontologia Preventiva e Social - Faculdade de Odontologia, UFRGS. Especialista em Odontologia Preventiva e Social - Faculdade de Odontologia, UFRGS.

** Professora Auxiliar de Ensino do Departamento de Odontologia Preventiva e Social - Faculdade de Odontologia, UFRGS. Especialista em Odontologia Preventiva e Social - Faculdade de Odontologia, UFRGS.
R. Fac. Odontol.

Porto Alegre
V. 33

N. 1

p.12-17

JULHO

1992 
diagnóstico coerente com os avanços científicos nesta área.

A palavra diagnóstico é derivada do grego, dia (através) e gnosis (conhecimento), é evidente, então, que um conhecimento completo dos fatores responsáveis pela etiologia e patogênese da doença é tăo importante quanto aqueles que permitem a sua identificação clínica. No processo de diagnóstico, a coleta de informaçōes relacionadas a esses fatores é decisiva para o sucesso do tratamento $(16,28)$.

No dia a dia, um dentista deve tomar inúmeras decisōes clínicas. Por trás da decisão de seguir um determinado caminho, está, naturalmente o conhecimento básico.

Muitos estudos têm mostrado que existem grandes variaçōes entre os dentistas nas suas decisōes de tratamento. Isso indica variaçōes no seu conhecimento básico ou que diferentes valores são atribuídos as inúmeras possibilidades de ação $(6,10,24,28)$.

\section{Avaliação da Atividade Cariogênica}

A avaliação da atividade cariogênica do paciente influencia o plano de tratamento, a seleção de materiais restauradores e a periodicidade de revisões para manutenção de saúde, embasando assim as várias decisōes no dia a dia do dentista.

Isto significa que há necessidade de registrar não só as cavidades, mas também sua localização e aspecto, bem como fatores e condiçōes que possam influenciar a atividade de doença e o posterior tratamento.

A anamnese é o primeiro passo para a avaliaçăo da atividade cariogênica do paciente. É comum, antes de examinar o paciente pela primeira vez, o dentista obter algumas informaçōes de caráter pessoal, importantes para o diagnóstico da atividade cariogênica.

O local onde o indivíduo mora, sua ocupação e condiçōes de vida, afetam tanto a saúde geral quanto a dentária e deverão ser investigados e registrados.

Muitas doenças sistêmicas e seu tratamento podem reduzir a resistência do paciente a cárie, alterando o equilíbrio do meio-ambiente bucal, por exemplo, muitas doenças e/ou medicamentos afetam a velocidade do fluxo salivar.

Os hábitos dietéticos e de higiene bucal, bem como o uso prévio de flúor também devem ser observados.

Durante o exame intra-oral, vários fatores devem ser investigados, entre eles: condições das membranas mucosas, prevalência de cárie, quantidade de placa, localização e característica das lesōes cariosas e qualidade do tratamento anterior.

Uma combinação de exame clínico e radiográfico é essencial para detectar todas as lesões cariosas.

A história dietética, a medição do fluxo e capacidade tampão da saliva e a análise de amostras bacteriológicas, são exames complementares que se fazem necessários quando 0 paciente apresenta um quadro de lesōes cariosas em atividade, uma necessidade de tratamento restaurador extenso e expectativa de alto risco de cárie $(16,31)$.

Como o objetivo deste artigo é a discussão do diagnóstico clínico da cárie dentária, não serão abordados com maiores detalhes os tópicos anteriormente mencionados, apesar de considerarmos que são de extrema relevância.

\section{Evolução do Diagnóstico Clínico e do Tratamento da Doença Cárie}

Quando năo se conhecia o processo da ocorrência da doença cárie, o tratamento era associado à existência ou não de dor e consistia na extração da peça dentária que a estava causando. Na Idade Média, os profissionais responsáveis pela extração dentária eram ferreiros e barbeiros. Ainda hoje muitos associam a figura do dentista ao profissional encarregado de extrair dentes.

Na metade do século XIX, começaram a ser desenvolvidos materiais restauradores no intuito de substituir a substância dentária perdida e interromper o processo da lesão de cárie, restabelecendo a funçăo do dente. $A$ doença cárie ainda era em grande parte desconhecida. O diagnóstico, entăo, resumia-se na detecçāo de cavidades de cárie, que hoje sabemos serem sequelas de uma doença que começou bem antes. Um inadequado conhecimento da etiologia e patogenia da doença transformava a restauração de dentes cariados em sinônimo de tratamento de cárie. A cárie nāo era encarada como uma doença infecciosa passivel de prevenção e controle e sim, como uma fatalidade ao qual o ser humano estava exposto.

No início do século $X X$, surgiram as "Leis de Black" que eram normas para confecção de cavidades em dentística onde era preconizado a extensão preventiva. A técnica da extensão preventiva na cavidade Classe I preconizava a remoção não só da lesão de cárie, mas também esmalte e dentina hígidos da região de sulcos e fissuras, levando a cavidade até a chamada região de "relativa imunidade à cárie" (região de cúspides e crista marginal). Essa preocupação era justificada pelo desconhecimento da possibilidade de controle das lesōes de cárie. Achava-se que em todo defeito de esmalte ou sobre uma superfície oclusal ocorreria acúmulo de placa, resultando necessariamente em cárie (28).

Hoje, através do conhecimento científico a respeito do processo de instalação e progressão da lesão de cárie, não podemos, de maneira nenhuma, conceber remoção de esma!te hígido como prevençāo. Além disso é possivel controlar o surgimento e a progressão da doença cárie sem necessidade, muitas vezes de tratamento restaurador.

Nos dias atuais, mesmo incompatível com o desenvolvimento científico nesta área, ainda existem trabalhos preconizando, entre outras técnicas, a extensão preventiva $(1,18)$. Dentro deste mesmo raciocínio é realizado o diagnóstico. Este é feito de maneira 
estática, não considerando o processo dinâmico ao qual está envolvida a doença cárie. Isto é de crucial importância, pois a postura do profissional será determinada por seu conhecimento deste processo. 0 conhecimento de que cárie não é um problema anatômico e sim todo um processo de doença multifatorial que deve ser reconhecido como um todo $(13,16,22,23,28)$.

O diagnóstico da doença cárie realizado a despeito da dinâmica do processo torna-se difícil de ser reproduzido. Alguns autores mostram a dificuldade de estandartização do mesmo diagnóstico num grupo de profissionais e, como consequência em relação ao tratamento subsequente $(6,10,24)$.

Merret e Elderton (20) comprovaram dificuldade de uniformidade de diagnóstico no estudo onde 228 dentes foram examinados por um grupo de 9 dentistas. Um dentista achou necessidade de tratamento em 28 dentes e outro em 119. Dos 228 dentes, 145 foram considerados cariados por um ou mais dentistas, mas apenas 17 destes tiveram unanimidade total por todo o grupo de examinadores. Outro trabalho realizado por Silva, Maltz e Franco (*) demonstrou năo haver concordância nenhuma na indicativa de tratamento das lesões de superfície oclusal, examinando-se 85 faces, o grupo era constituído de 15 examinadores.

Quando analisamos dados deste tipo, devemos concluir que existe um equívoco muito grande em relação ao diagnóstico de cárie. Este pode ser atribuído ao não uso do conhecimento científico no diagnóstico clínico de cárie. $O$ exame não é realizado levando-se em conta o paciente como um todo, a sua atividade de cárie, resumindo-se muitas vezes ao simples "trancar" da sonda exploradora (12).

Muito deste enfoque em relação a doença, advinha do fato de que se considerava o esmalte uma estrutura inerte, desconhecendo-se o fato de existir uma camada externa onde ocorrem constantemente trocas com o meio ambiente bucal. Era totalmente desconhecido tanto o fenômeno de des-remineralização quanto o mecanismo de ação do flúor que interfere positivamente neste processo $(7,25)$.

Assim sendo com o conhecimento dos fatores etiológicos da cárie, do mecanismo de ação de doença de maneira individual, podemos diag nosticar e intervir de forma diferente.

\section{Como deve ser realizado o diagnóstico de cárie?}

Primeiramente, a placa dental é totalmente removida. A iluminação deve ser boa e os dentes secos. O ideal é se fazer isolamento relativo da saliva, para facilitar a visualização das lesões. Com o uso de espelho bucal e sonda exploradora examinaremos as faces dentais uma a uma. $\mathrm{O}$ uso da sonda exploradora será questionado e discutido mais adiante. No exame clínico, o que se quer diagnosticar é o número de lesōes, sua localização e atividade. São consideradas lesões ativas aquelas que quanto ao esmalte, apresentarem-se rugosas, branco-opacas e, quanto a dentina, amolecidas e claras. São consideradas lesōes inativas aquelas que no esmalte não apresentarem opacidade e, quanto a dentina, forem escuras e com maior dureza que as lesōes ativas. É importantíssimo, para classificaçăo de atividade, detectarmos as lesões iniciais de cárie, as manchas brancas. Estas, são lesões branco-opacas rugosas que aparecem no esmalte antes da cavitação $(16,23,27)$.

\section{Diagnóstico e tratamento da cárie de superfície lisa}

As lesões de superfície lisa livre localizam-se na zona cervical das superfícies vestibulares e linguais, caracterizam-se por estenderem lateralmente mais do que em profundidade $(22,23)$.

Quanto a superfície lisa livre existem trabalhos que mostram a possi- bilidade de controle das lesōes cariosas destas superfícies mesmo quando cavitadas sem a necessidade de tratamento restaurador. Hoje existem critérios que determinam quando devemos restaurar. Estes critérios são: estética, funçăo, dor e envolvimento pulpar. Outro critério é aquele que diz respeito a possibilidade de remoção do fator etiológico placa dental em cavidades muito retentivas. Onde isto se torna impossível, a restauração é indicada $(12,13)$.

As lesōes cariosas interproximais localizam-se nas superfícies mesiais e distais logo abaixo do ponto de contato, quando cavitárias muitas vezes são visíveis clinicamente e na fase de mancha branca em geral só são diagnosticadas radiograficamente $(22,23,28)$.

$\mathrm{Na}$ superfície lisa interproximal, o tratamento estará associado a presença ou não de cavidade. Se a cárie ainda está em fase de mancha branca, o tratamento será o mesmo dado a qualquer mancha branca de superfície livre, isto é controle dos fatores etiológicos e fluorterapia. A cavidade em superfície proximal torna impossível a remoção da placa dental fazendo com que a opção de tratamento seja a restauradora.

Muitas vezes, clinicamente, podemos saber se existe ou não cavidade, quando houver dúvida utilizaremos o exame radiográfico. Existem trabalhos mostrando a correspondência entre o exame radiográfico e o clínico (29). Estes mostram que quando a radiolucidez indicando cárie estiver apenas em esmalte, em 70 a 80 por cento dos casos a lesão ainda é mancha branca $(2,19)$. Então nestes casos, o tratamento consistirá em controle dos fatores etiológicos e flúor, sem esquecer é claro do acompanhamento radiográfico periódico.

(*) SILVA, B.B.; MALTZ, M.; FRANCO, F. Diagnostic and treatment of occlusal caries - variation among examiners. Trabalho selecionado para apresentaçāo no Encontro Anual da International Association of Dental Research, Glasglow, Escócia, jul. 1992. 


\section{Diagnóstico e Tratamento da cárie de superfície oclusal}

Em relação a face oclusal se tinha a idéia de que toda a superfície oclusal ia acabar mais cedo ou mais tarde cariando pelo simples fato de que é um local retentivo de mais difícil higienização. $\mathrm{Na}$ década de 20 , baseados no fato da impossibilidade de limpeza da superfície oclusal e que esta necessariamente iria cariar foram desenvolvidas diversas técnicas invasivas: primeiro a odontomia profilática (remoção da entrada das fissuras para facilitar a limpeza), logo após as restauraçōes preventivas que propunham a obliteração de sulcos saudáveis preventivamente. Nesta mesma linha de raciocínio está a extensão preventiva de Black que preconizava mesmo em uma lesão de cárie de ponto, estender e restaurar toda a fissura porque era certo que o restante da superfície oclusal viria a cariar $(15,28)$. Dentro do mesmo ponto de vista, temos também os selantes, que vieram na década de 70 , numa visão fatalista de que era impossível controlar-se o aparecimento da lesão de cárie oclusal, obliteravam-se sulcos e fissuras hígidos para prevenção.

Atualmente, não existe justificativa que indique a obliteraçāo de todos os sulcos e fissuras. Com o controle da doença cárie como um todo fica cada vez menos justificável economicamente selar todas as faces oclusais indiscriminadamente, isto deve ser considerado como sobretratamento $(13,21)$. Em sua tese de doutorado, Carvalho (5) comparou os resultados de um programa preventivo de controle da doença cárie com o tratamento dado por um atendimento odontológico convencional numa ilha dinamarquesa. Neste grupo controle, as crianças tinham seus dentes permanentes selados assim que irrompiam na cavidade bucal enquanto que nas crianças do grupo teste submetidas ao programa odontológico preventivo, os resultados mostraram năo haver necessidade de selamento dos dentes na grande maioria das crianças $(3,4)$.
Muitos trabalhos mostram um grande número de desmineralizações em superfície oclusal passiveis de inativação como qualquer mancha branca de superfície lisa. Estas manchas brancas em face oclusal sāo muito comuns em molares que estão em fase de erupção pela dificuldade de acesso a limpeza. $\mathrm{Na}$ maioria das vezes, o simples fato do dente entrar em oclusão faz com que elas inativem.

Em relação ao diagnóstico da lesão de cárie de superfície oclusal, existe um questionamento muito grande quanto ao uso da sonda exploradora. No estudo de Penning e colaboradores (26), observa-se que para o diagnóstico de cáries oclusais, a sonda exploradora diagnosticou apenas $24 \%$ das lesões detectadas histologicamente. Além deste fato, Ekstrand e Thylstrup (8) ressaltam que o uso clássico da sonda exploradora pode produzir efeitos traumáticos irreversíveis em áreas desmineralizadas na superfície oclusal, favorecendo condiçōes para progressão da lesão. A partir destes estudos se tem que a sonda pode muitas vezes não ser fiel ao diagnóstico e causar iatrogenia $(8,26)$.

Vários trabalhos sustentam que a superfície oclusal é passível de controle da doença cárie como qualquer outra superfície. Aquilo que se tinha anteriormente afirmando que toda a fissura iria cariar pela retenção mecânica de placa não é verdadeiro: primeiro porque as bactérias no fundo da fissura não são viáveis, podendo inclusive constituir-se muitas vezes em uma placa calcificada; e segundo que a lesão de cárie inicia nas paredes laterais da entrada da fissura, local de acesso à higiene e a ação do flúor $(9,23,28)$.

Hoje, o diagnóstico deve ser realizado coerente com o conhecimento científico nesta área. $O$ objetivo do exame deve ser primeiramente detectar a atividade de cárie do paciente e o tratamento deve ser voltado para a inativação deste processo (16).

\section{Discussão}

\section{Diagnóstico visual $x$ Validade do uso da sonda exploradora}

O exame visual por si só nos dá uma informação semelhante ao exame táctil-visual combinado sem provocar iatrogenia (23). Esta afirmativa se justifica em função do aspecto das lesōes cariosas. Por exemplo, a lesão de cárie inicial caracteriza-se pela perda da translucidez do esmalte que toma o aspecto de uma mancha branca, opaca e cuja superfície apresenta-se rugosa quando sondada, entretanto a sondagem deve ser evitada, pois a estrutura poderá romper-se, impossibilitando a remineralizaçăo (9).

Uma lesão cariosa em dentina que progride rapidamente é caracterizada pelo aspecto mole e úmido, a cor é castanho clara e o bordo da cavidade apresenta-se como uma lesão branca, Uma lesão pigmentada, de cor castanho-escuro a negro, indica uma evolução lenta $(16,23,28)$. Para que estas características possam ser observadas constituem-se em condições indispensáveis para um diagnóstico adequado, a limpeza dos dentes do paciente, a secagem das superfícies dentais e a iluminação apropriada do local.

\section{Tratamento da atividade de cárie $x$ Tratamento restaurador}

Dentro desta nova visão do processo dinâmico da doença cárie devemos analisar o que é considerado tratamento. Antigamente se tinha como resolução do problema, a confecção de restaurações nos dentes afetados pela cárie, mas como não se intervinha na etiologia, a doença, muitas vezes, continuava a existir. Atualmente, o nosso objetivo é analisar a atividade da doença e tratar esta atividade (28). Dispomos hoje de conhecimento suficiente para intervir diretamente na etiologia da doença. O tratamento restaurador é uma das medidas muitas vezes tomadas no tratamento, mas não a única. É possível termos o indivíduo completamente tratado sem ter tido nenhum tratamento restaurador invasivo. O que se quer com isto é manter ao ' máximo o tecido sadio. 
O tratamento da doença cárie é considerado, então, como o controle dos fatores etiológicos que interagem para que ela ocorra fazendo com que fiquem a um nível mínimo, provocando a inativação do processo (16). Aliando-se ao controle de placa e da dieta, está o flúor que tem um papel importantíssimo no tratamento da lesão de cárie. Um dos objetivos do tratamento da lesão de cárie é que facilite a remineralização da estrutura e esta remineralização é promovida mais eficientemente na presença de flúor.

0 tratamento restaurador tem um papel importante no controle dos fatores etiológicos da doença quando realizado adequadamente como já foi mencionado anteriormente, pois ele impede a retenção mecânica de placa, fazendo com que o controle da doença se torne mais efetivo (12). No entanto, restauraçōes com excesso ou falta de material passam a ser focos de retenção de placa dental, principalmente quando localizadas cervicalmente $(12,13)$.

O que determina se uma cavidade deve ou năo ser restaurada, não é de forma alguma seu envolvimento em dentina, ou seja, a presença de microrganismos já em dentina não significa a impossibilidade de estagnação do processo de cárie. Existem trabalhos comparando dados clínicos e histológicos que mostram cavidades de cárie em dentina inativas clinicamente e ao corte histológico podemos detectar invasão microbiana. $O$ que se pensa é que, provavelmente, estes microrganismos estejam inviáveis para continuarem o ataque cariogênico (28).

Ao ponderarmos a decisão de restaurar ou não, deve-se levar em conta que por mais perfeito que seja 0 preparo cavitário e mesmo sendo usado o melhor material restaurador possivel, a média de durabilidade das restauraçōes tem sido de 5 a 10 anos. Sendo assim, uma restauração por mais bem feita que seja não substitui o tecido dentário hígido. Por isto na dúvida, espere, observe e tente estacionar o processo da doença $(11,13,30)$.

\section{Troca de Restauraçōes}

O padrão para troca de restauraçōes também está mudando em decorrência do conhecimento científico. $O$ que se quer é manter o máximo de estrutura hígida dental e sabe-se que a cada troca de restaurações, uma certa quantidade de estrutura sadia é perdida. Atualmente só está indicada a troca de restauraçōes quando houver uma fratura de tamanho significante que retenha placa e prejudique a função e, é claro, na presença de recidiva de cárie.

Procura-se incentivar o recondicionamento dos amálgamas antigos com técnicas de polimento e brocas especiais que possibilitem uma nova lisura e escultura no amálgama restabelecendo o seu papel e restaurando a sua funçāo.

Estudos in vivo têm mostrado que restauraçōes recolocadas frequentemente contém os mesmos erros que suas antecessoras. Além disso, pessoas que trocaram de dentista pelo menos uma vez em cinco anos têm mais restaurações, em média 13,6 comparada com 7,4 daquelas que permaneceram com o mesmo dentista $(11,12,13)$.

\section{Conclusão}

O diagnóstico e a indicativa de tratamento em relação à cárie dental está passando por uma mudança no seu paradigma. Cabe aos dentistas aproveitar o nível de conhecimento atual do processo cárie dental e a possibilidade de intervenção nos fatores que a desencadeiam, para que se mantenha ao máximo a estrutura dental hígida. O conhecimento em relação à cárie está evoluindo a cada dia e temos que estar atentos para que possamos oferecer aos nossos pacientes uma Odontologia Moderna. Quando houver dúvida a respeito da evolução ou năo da doença devemos manter o paciente sob controle, nunca instituindo drasticamente um tratamento invasivo irreversível.

Quando se entende o tratamento da doença cárie desta maneira, os materiais restauradores ou a técnica restauradores em si, que a princípio detinham o papel principal na resoluçăo do problema, assumem o papel de auxiliar no controle da doença. A evolução dos materiais restauradores possibilitará a remoção apenas do tecido cariado sem necessidade de perda de estrutura sadia com finalidade de retenção do material. Dos materiais já testados existem aqueles que permitem aderência física e biológica à estrutura dental (resinas compostas, ionômero de vidro). O que se espera é que estes materiais tenham ainda algumas propriedades que apenas 0 amálgama tem, como resistência e durabilidade, sem o inconveniente da necessidade de cavidades retentivas que fazem com que se perca estrutura dental sadia.

É importante ressaltar que, embora tenhamos um conhecimento relativamente complexo no que respeita a doença cárie, muito permanece ainda por ser descoberto. Vale mencionar que isto é verdadeiro com relação aos métodos envolvidos no processo de diagnóstico e no uso das informações obtidas visando a decisão de tratamento. Investigações futuras nos proverão com novos conhecimentos que deverão ser incorporados pelos cirurgiōes-dentistas para atenderem com sucesso os seus pacientes. 


\section{REFERÊNCIAS BIBLIOGRÁFICAS}

01. BARATIERI, L.N. et al. Dentística: Procedimentos preventivos e restauradores. 3.ed., São Paulo: Quintessence, 1989.

02. BILLE, J.; THYLSTRUP, A. Radiographic diagnosis and clinical tissue changes in relation to treatment of approximal carious lesions. Caries Research, Basel, Sweden, v.16, p.1-6, 1982.

03. CARVALHO, J.C.; EKSTRAND, K.R.; THYLSTRUP, A. Dental plaque and caries on occlusal surfaces of first permanent molars in relation to stage of eruption. Journal of Dental Research, Washington, v.68, n.5, p.773-779, may, 1989.

04. CARVALHO, J.C.; EKSTRAND, K.R.; THYLSTRUP, A. Results after 1 year of non-operative occlusal caries treatment of erupting permanent first molars. Community Dental Oral Epidemiology, Copenhagen, v.19, p.23-8, 1991.

05. CARVALHO, J.C. Non-operative treatment of occlusal caries. Thesis. Department of Cariology and Endodontics, Royal Dental College, Copenhagen, Denmark, 1992.

06. CLEATON-JONES, P. et al. Dental caries diagnosis calibration for clinical field surveys. Caries Research, Basel, Sweden, v.23, p.195-199, 1989.

07. CURY, J. Cariologia. In: BARATIERY, L.N. et al. Dentística: Procedimentos preventivos e restauradores. 3.ed., Sāo Paulo: Quintessence, 1989, cap.2, p.4-68.

08. EKSTRAND, K.; QVIST, V.; THYLSTRUP, A. Light microscope study of the effect of probing in occlusal surfaces. Caries Research, Basel, Sweden, v.21, p.368-374, 1987.

09. EKSTRAND, K.R. et al. Okklusal caries. Naturhistorie. TNT, Copenhagen, n.4, p.5-13, april, 1988.

10. ELDERTON, R.J.; NUTALL, N.M. Variation among dentists in planning treatment. British Dental Journal, London, v.154, p.201-206, 1983.

11. ELDERTON, R.J. Longitudinal study of dental treatment in the General Dental Service in Scotland. British Dental Journal, London, v.155, p.91-6, 1983.
12. ELDERTON, R.J. (ed.) Positive dental prevention: The prevention in childhood of dental disease in adult life. London: Heinemann Medical, 1987, 146 p.

13. HORSTED-BINDSLEV, P.; MJOR, I.A. Modern concepts of operative dentistry. Copenhagen: Munksgaard, 1988.

14. KEYES, L. et al. The infections and transmissible nature of experimental dental caries. Findings and implications. Archives of Oral Biology. Oxford, v.1, p.304-320, 1960.

15. KONING, K.G. Dental morphology in relation to caries resistance with special reference to fissure as susceptible areas. Journal of Dental Research, Washington, v.42, sup. n.1, p.461-476, 1963.

16. KRASSE, B. Risco de cárie. Sāo Paulo: Quintessence, 1986.

17. MALTZ, M. Antimicrobial effects on bacteria associated with dental caries. Thesis. Department of Cariology, Faculty of Odontology. University of Goteborg. Goteborg. Sweden, 1981.

18. MEIERS, J.C.; JENSEN, M.E. Management of the questionable carious fissure: Invasive vs noninvasive techniques. Journal American Dental Association, Chicago, v.108, p.64-68, jan. 1984.

19. MEJARE, I. et al. Accuracy at radiography and probing for the diagnosis of proximal caries. Scandinavian Journal of Dental Research, Copenhagen, v.93, p.178-184, 1985.

20. MERRET, M.C.W.; ELDERTON, R.J. An in vitro study of restorative dental treatment decisions and dental caries. British Dental Journal, London, v.157, n.4, p.128-133, aug. 1984.

21. MITCHELL, L.; MURRAY, J. Fissure sealants: a critique of their cost-effectiveness. Community Dental Oral Epidemiology, Copenhagen, v.17, p.19-23, 1989.

22. NEWBRUN, E. Cariologia. 2.ed. São Paulo: Santos, 1988.

23. NIKIFORUK, G. Understanding dental caries: etiology and mechanisms basic and clinical aspects. New York: Kargej 1985 , v. 1 .
24. NUTALL, N.M. Capability of a national epidemiological survey to predict General Dental Service treatment. Community Dental Oral Epidemiology, Copenhagen, v.11, p.296-301, 1983.

25. OGAARD, B. Effects of fluoride on caries development and progression in vivo. Journal of Dental Research, Washington, v.69 (Spec Issue), p.813-819, feb. 1990.

26. PENNING, J.P. et al. Validity of probing for fissure diagnosis. Caries Research, Basel, Sweden, v.25, p.216, Abstract 14, may/jun, 1991.

27. SILVERSTONE, L.M. et al. Dental caries. A etiology pathology and prevention. London: Macmillan Publishers, 1985.

28. THYLSTRUP, A.; FEJERSKOV, O. Tratado de cariologia. Rio de Janeiro: Cultura Médica, 1988.

29. VRIES, H.C.B. et al. Radiographic versus clinical diagnosis of approximal carious lesions. Caries Research, Basel, Sweden, v.24, p.364-370, sep./oct. 1990.

30. WALLS, A.W.G. et al. The longevity of occlusal amalgam restorations in first permanent molars of child patients. British Dental Journal, London, v.158, p.133-136, feb. 1985.

31. WEYNE, S. Cariologia. In: BARATIERI, L.N. et al. Dentística: Procedimentos preventivos e restauradores. 3.ed. Sāo Paulo: Quintessence, 1989. Cap.1, p.1-42.

32. ZICKERT, I. Prevention of dental caries. Studies on the effect of some methods. Thesis. Department of Cariology, Faculty of Odontology, University of Goteborg, Sweden, 1982.

\section{R. Fac. Odontol.}

N. 1 p.12-17 SIDADE FEDERAL DO RIO GRANDE
FACULDADE. DE ODONTOLOGIA FACULDADE. DE OTECA
BIBLIOTEC 